\title{
Adaptive Knowledge Management of Project-based Learning
}

\author{
Oleg Tilchin ${ }^{1}$, Mohamed Kittany ${ }^{1}$ \\ ${ }^{1}$ Al-Qasemi Academic College of Education, Baqa El-Gharbieh, Israel \\ Correspondence: Oleg Tilchin, Computer Science Department, Academic College of Education, P.O. Box 124, \\ Baqa El-Gharbieh 30100, Israel
}

Received: March 15, 2016 Accepted: March 21, $2016 \quad$ Online Published: March 25, 2016

doi:10.11114/jets.v4i6.1461

URL: http://dx.doi.org/10.11114/jets.v4i6.1461

\begin{abstract}
The goal of an approach to Adaptive Knowledge Management (AKM) of project-based learning (PBL) is to intensify subject study through guiding, inducing, and facilitating development knowledge, accountability skills, and collaborative skills of students. Knowledge development is attained by knowledge acquisition, knowledge sharing, and knowledge utilization. The determined conceptual framework shapes an adaptive process for managing knowledge. The process realizes adaptive self-formation of knowledge-heterogeneous collaborative groups of students, adaptation of an instructor's assessments to knowledge dynamics of individual students and collaborative groups, dynamic choice of control tests for individual students and projects of suitable complexity for collaborative groups, and adjustment of an instructor's control questions to complexity levels of projects performed by groups. The accountability skills are developed by creating and sharing accountability of students for successful performance of projects. The development of collaborative skills is resulted by collaborative performance of the projects. AKM of PBL is realized by two phases. The first phase is devoted to planning teaching and learning the subject matter. The second phase is aimed at promoting development of knowledge, accountability and collaborative skills of students through guiding performance of the sample project, monitoring and assessing the sample project outcome, fostering students' adaptive grouping, organizing collaborative performance of the group projects.
\end{abstract}

Keywords: project-based learning, adaptive knowledge management

\section{Introduction}

In today's competitive knowledge-based economy the concept of knowledge management (KM) has become increasingly prevalent for teaching and learning (Quinn, Anderson \& Finkelstein, 1998; Livingstone \&Guile, 2012; Rooney, Mc Kenna \& Liesh, 2014). KM of learning is aimed at knowledge development of students through knowledge acquisition, knowledge sharing, and knowledge utilization (Tiwana, 1999; Petrides \& Nodine, 2003; Dalkir \& Liebowitz, 2011; Edwards, 2015). Knowledge acquisition is the process caused by knowledge creation. Knowledge sharing is the process disseminating and making available what is already known. Knowledge utilization comes in process of doing.

To ensure effective KM of students a special learning environment should be created. The learning environment should keep students active, constructive, collaborative, intentional, complex, contextual, conversational, and reflective (Jonassen, 2004; Doyle \& Taqq, 2008). Analysis of various methods, models and means of organizing teaching and learning tells us that creation of the learning environment with the above-mentioned properties is possible based on the joint use of project-based learning (PBL) and collaborative learning models (Thomas, 2000; Barkley, Cross \& Howell, 2004 ). Knowledge management approach to PBL promotes knowledge development of students through combining all the essential learning environment properties in a natural and effective way (Biggs, 2003; Jonassen, 2004).

Effective KM process should be adaptive (Sherif, 2006; Mcinerney \& Day, 2007; Zaim H., Tatoglu, \& Zaim S., 2007; Dalkir \& Liebowitz, 2011). Adaptability of KM allows taking action to improve knowledge development of students while performance projects based on the results of monitoring. Requirement of providing KM adaptability and finding the correct balance between personalized and collaborative learning causes the need of enhancing of PBL (Sallis \& Jones, 2002).

Enhancing PBL consists in realization of subject study through two stage process of PBL. Each student from a class performs individually a same project (sample-project) on first stage of PBL. The purpose on this stage is promotion of creation of subject-relevant knowledge, and acquisition of PBL skills due to adoption of specificity of PBL environment. 
Monitoring and assessment of students' learning outcome after completion of the sample-project allows adaptive process for managing knowledge on the second stage of PBL. The purpose on this stage is promoting development of higher-order knowledge and soft skills (i.e., communications, collaboration, learning to learn, and emotional intelligence) in students. Development of higher-order knowledge is realized through knowledge sharing and knowledge utilization while projects' performance by collaborative groups.

The goal of the proposed approach is to determine conceptual framework and to develop an adaptive knowledge management (AKM) process of PBL promoting effective development knowledge, collaborative skill and accountability skill in students.

\section{Related Research}

The approaches, methods, models, and tools promoting effective development of knowledge and aforementioned skills are examined here relative to various aspects. The aspects are management of PBL, KM of learning, and adaptive learning support.

\subsection{Management of PBL}

Mergendoller \& Thomas (2005) determined principles of managing PBL and grouped their under seven categories. The categories are: time management, getting started, establishing a culture that stresses student self management, managing student groups, working with others outside the classroom, getting the most out of technological resources, and assessing students and projects. Mergendoller et al.(2006) developed a "pervasive" four stage management approach to guide students effectively through the PBL process. The stages are - project planning, project launch, guided inquiry and product creation, and project conclusion. Management activities guiding and facilitating students' PBL are determined relative to each stage. Orvis \& Lassiter (2008) investigated dynamic management of group organization.

\subsection{KM of Learning}

Garner (2010) ascertained relation between personal KM and learning. The author proposed the seven components of personal KM and connected them with elements of a learning framework developed by Oliver \& Herrington (2001). The framework comprises three critical elements: learning content; learning activities; and learning supports. The components of PKM are retrieving content, assessing information, organizing the information, analyzing the information, collaboration, securing information, presenting information.

Markham (2012) suggested an approach to specific management of project performance directed towards creation of higher-order knowledge through collaboration. Stanton \& Fairfax (2007) defined a productive collaborative environment as one in which there is interdependence of the students on face-to-face interaction and on development of collaborative skills. Successful formation of groups is provided by means of going through the following stages: structuring of learning activities, creation of groups, and facilitation of group interactions (Graham \& Misanchuk, 2003).

Facilitation of group interactions should be understood as creation of situations leading to group interactions. Thus, "the situation generates interactions, and these interactions trigger cognitive mechanism" (Dillenbourg, 1999). Various methods and means directed towards facilitation of group interactions are suggested in works (Ettington \& Camp, 2002; Dongsik \& Seunghee, 2002; Lopez et al., 2002; Weinberger et al., 2003).

\subsection{Adaptive Learning Support}

Burgos, Tattersall \& Koper (2006) proposed different types of adaptive learning support including problem-solving support, information filtering, collaborative grouping of students, adaptive testing and real-time course modifications by the instructor to meet the specific needs of students. According to the authors, modern adaptive systems provide four key approaches to personalized learning based on student learning goals, adjusting the type of instruction used to the needs or preferences of the student, adapting based on learning behavior of students, and collaborative learning.

Soller (2007) described various tools of adaptive support for collaborative learning to promote facilitation of interactions, motivation for knowledge sharing, and collaboration management. Mennin (2007) investigated a PBL group as a complex adaptive system. A student group is complex and it is adaptive in that the participants individually and in a group are altered.

Brusilovsky\& Maybury (2002) defined an adaptive system as one that distinguishes between users including their knowledge goals and interests, and an adaptable system as one requiring the user to specify exactly how the system should be different. Brusilovsky \& Peylo (2003) considered adaptive group formation using knowledge about collaborating peers, and adaptive collaboration support providing an interactive support of a collaboration process assisting an individual student in solving a problem.

Aguilar \& Kaijiri (2007) developed an adaptive computer-based assessment system, which provides initial, formative, 
and summative assessments. The system generates questions adapted to the learners' knowledge. Lazarinis, Green \& Pearson (2010) proposed Computerized Adaptive Testing (CAT) system, which adapts based on student performance, instructional goals, and test participants existing knowledge of the subject matter. The authors provided examples where instructors set different adaptive assessments for various scenarios. Papanastasiou (2014) defined adaptive assessment as one that is specific for each student and takes into account that student's previous performance, thus making it more accurate in terms of individual ability.

\subsection{Consequence}

The publications discussed above indicate that no comprehensive approach exists to AKM of PBL. The proposed complex approach will promote effective development of student knowledge in the PBL environment due to:

- Organizing a subject study as two-stage PBL

- Determining conceptual framework for AKM

- Finding the correct balance between personalized and collaborative learning

- Detailed planning knowledge development of students

- Developing adaptive process for managing knowledge

- Inducing, guiding, and facilitating knowledge acquisition, knowledge sharing, and knowledge utilization.

\section{Adaptive Knowledge Management of PBL}

The goal of AKM of students in PBL environment is to intensify subject study through inducing, guiding, and facilitating development of knowledge, accountability skills, and collaborative skills of students. Knowledge management in PBL environment is aimed at knowledge acquisition, knowledge sharing, and knowledge utilization. The adaptability of KM allows adjusting to knowledge dynamics of students. The accountability skills are developed by creating and sharing accountability of students for successful performance of projects. The development of collaborative skills is resulted by collaborative performance of the projects. The adaptive process for managing knowledge is shaped by the determined conceptual framework. AKM of students is realized by two phases: planning knowledge development, and adaptive management of knowledge development.

\subsection{A Conceptual Framework for AKM of PBL}

A conceptual framework is devoted to guiding design of the adaptive process for managing knowledge. The framework comprises concepts:

A comprehensive PBL environment. A comprehensive PBL environment is characterized as student-centered, knowledge and skill-centered, community-centered, assessment-centered, accountability-centered, and computer support-centered.

The student-centered characteristic means students' independence in learning by doing, combining individual and collaborative learning, adaptability to each student, and encouraging student interest in problem solving and critical thinking.

The knowledge and skill-centered characteristic assumes the instructor's concentration on development knowledge, and soft skills in students.

The community-centered characteristic means group work in PBL environment to develop knowledge and skills collaboratively. It requires group interdependence, motivation, compatibility, and sociability.

The assessment centered characteristic means high quantity and quality of assessments while maintaining students' interest to development of knowledge and skills. An assessment should be guided and adaptive process and promote responsibility for learning results.

The accountability-centered characteristic means taking accountability of students for one another's learning as well as their own. It leads to the progress of individual students and does not on averages of large groups of students who not share similar learning needs.

The computer-centered characteristic means computer support of PBL through using possibilities of computer technologies for providing effective learning and decreasing an extra-heavy workload for an instructor.

The complexity of KM. The complexity of KM is caused by the need of management of knowledge on all its levels. The knowledge levels are know-what, know-how, know-why, and care-why. The knowledge levels have their determined roles in education. Thus, the know-what level represents cognitive knowledge; the know-how level deals with practical problems of design based on a synthesis of knowledge; the know-why level refers to deep knowledge of complex cause-and-effect relationships; the care-why level represents self-motivated creativity. The most important soft 
skills considered in this research are collaborative skills and accountability skills.

A two- stage study of a subject in the PBL environment. It is aimed at developing knowledge, collaboration and accountability skills of students during the PBL of a subject.

The purpose of an instructor on first stage is promoting knowledge creation by students (it is basically knowledge of know-what and know-how levels relevant to subject), and fostering adoption of specificity of PBL environment.

An instructor teaches a subject while performing tasks of a sample-project by each student of the class during this stage. It provides performance of the corresponding task (tasks) of a sample project, since educational matter of each subject topic corresponds with one task or some tasks.

Then, knowledge of every student is examined relative to knowledge levels through the personal control questions based on subject matter. It allows assessing knowledge development. Next, adaptive self-formation of knowledge-heterogeneous collaborative groups based on the assessment results of individual students is realized.

The main attention of an instructor on second stage is devoted to promoting development of higher-order knowledge (it is knowledge of know-why and care-why levels), inducing development of collaboration and accountability skills, and facilitating the acquisition of PBL experience. Development of higher-order knowledge is realized through knowledge sharing and knowledge utilization during performance of projects by collaborative groups. Then, knowledge of students is assessed through control tests and examination of group projects. The choice of control tests is triggered by the assessments of students' knowledge after the first stage.

The complexity of assessment. The complexity of assessment is caused by availability of assessments needed for AKM, and assessments of subject study. Assessments needed for AKM are initial, formative, and adaptive assessments of students' knowledge. Assessments of subject study include assessments of students' knowledge after completion of the sample-project and the group projects, assessments of group projects, assessments of accountability skills and collaborative skills, complex summative assessments of students.

Adaptability of KM is expressed by adaptive self-formation of knowledge-heterogeneous collaborative groups of students, adaptation of an instructor's assessments to knowledge dynamics of individual students and collaborative groups, adaptive choice of the project of suitable level of complexity for the collaborative group, dynamic choice of control tests for monitoring and assessment of individual students, and adjustment of an instructor's control questions to complexity levels of projects performed by collaborative groups.

\subsection{Planning Knowledge Development of Students}

This phase of AKM comprises the planning directions: specification of a subject, specification of a sample-project, setting initial assessments of subject study, specification of group projects.

Specification of a subject includes:

- Forming a list of subject topics

- Setting requirements for a student. After studying a subject, a student should know its concepts, get results by applying theoretical knowledge, explain cause-and-effect relationships, and make creative decisions.

- Determining subject-relevant knowledge and conditions for development of collaboration and accountability skills. Subject-relevant knowledge is aggregate topic-relevant knowledge, which is required knowledge of above mentioned levels related to a subject topic.

- Creating control tests for examination of subject-relevant knowledge of an individual student after completion of a sample-project.

Specification of a sample-project includes:

- Establishment of correspondence between a subject and a sample-project relative to the required knowledge. Knowledge needed for performance of the sample-project (sample project-relevant knowledge) should be equal to subject-relevant knowledge.

- Determining a set of project tasks and the order of their performance. A set of project tasks should correspond with a set of subject topics. It means that one task or some tasks of a sample-project should correspond to each subject topic. The order of teaching subject topics is conformed to the order of tasks' performance.

- Defining task-relevant knowledge (it is knowledge needed for performance of a task)

- Setting correspondence between topic-relevant knowledge and task- relevant knowledge.

Setting initial assessments of subject study embraces: 
- Setting the initial assessments of students' knowledge for different knowledge levels. The more initial assessments are set for know what and know-how of knowledge levels. It is aimed at motivation and involvement of students in subject study and adoption of specificity of PBL environment.

- Setting the initial assessments of knowledge of students relative to subject topics and tasks of the sample-project

Specification of group projects represents descriptions of projects of different levels of complexity. A group project has more complexity level, if more higher-order knowledge is required for its performance. The specification includes:

- Determining knowledge needed for performance of group projects

- Forming a list of control tests of different complexity for examination of students' knowledge after completion of group projects

- Setting fixed assessments of accountability and collaborative skills of students

- Setting fixed assessment of collaborative performance of group projects

- Setting deadline for completion of group projects.

\subsection{Adaptive Management of Knowledge Development}

This phase of AKM aimed at promoting development all levels knowledge, accountability skills, and collaborative skills of students. It includes the management directions: guiding performance of the sample-project, fostering adaptive self-formation of knowledge heterogeneous collaborative groups, organizing collaborative performance of group projects.

Guiding performance of the sample-project includes:

- Teaching of a subject while student performance of sample-project tasks. It allows the creation of subject knowledge of know-what and know-how levels by students.

- Determining formative assessments of students' knowledge relative to the knowledge levels and the total formative knowledge assessment for each student after completion of the sample-project. The formative assessment of student knowledge is a sum of assessments of his (her) knowledge for all knowledge levels. Assessment is realized by the instructor through control questions regarding different knowledge levels.

Fostering self-formation of knowledge heterogeneous collaborative groups comprises:

-Determining the requirements for forming collaborative groups. The requirements induce students to compensation for the lack of individual knowledge concerning know-what, and know-how levels, and development of higher-order knowledge through collaborative interactions during performance of group projects.

The requirements are: cumulative knowledge built by study group students should not be less then sample project-relevant knowledge. It promotes performing group projects owing to inter-groups interactions; maximum mutual supplementation of knowledge of students inside a collaborative group. It promotes successful performance of group projects owing to intra-group interaction; taking into account personal characteristics of students. It fosters compatibility of students; maximal allowed quantity of students in a collaborative group is fixed. It encourages intensive collaboration of students.

- Promoting self-formation of collaborative groups. It consists in facilitation and stimulation of mutual choice by students of suitable peers for collaboration and following coordination, and adjustment among students of study group. The mutual choice, coordination, and adjustment are guided by the knowledge assessments received by students as a result of the sample-project performance, and the requirements for forming the collaborative groups.

Organizing collaborative performance of group projects comprises:

- Determining the group-relevant knowledge. It is cumulative knowledge created by students belonging to the collaborative group. Presence of this knowledge is defined by formative assessment of student group knowledge. This assessment is calculated as sum of formative knowledge assessments received by students from a collaborative group after completion of individual performance of the sample-project.

- Assigning projects for collaborative groups. It is realized by choice of a project of suitable complexity level for a collaborative group through comparison between complexity levels of projects and formative assessments of student groups' knowledge. The project of more high complexity level is assigned for the group having the more high formative assessment.

- Setting adaptive assessments of knowledge for individual students. The adaptive assessments are set on the basis of the formative assessments of student knowledge received after completion of the sample-project. If the formative 
assessment of student knowledge regarding some knowledge level is low, then adaptive assessment corresponding with this knowledge level is set by more high. Owing to that, adaptability of assessment to performance of an individual student is provided. It motivates a student to develop lacking knowledge during collaborative performance of a group project.

- Setting adaptive assessments of knowledge for collaborative groups. These assessments are set by taking into account formative assessments of collaborative groups. The more high adaptive assessment is set for the group having the more high formative assessment. Owing to that, adaptability of assessment to collaborative group knowledge is provided. It induces students of the collaborative group to effective performance of the group project.

- Building a structure of project tasks. It consists in promotion of setting interdependence of project tasks, and facilitation of formation of a temporal sequence of project tasks. The temporal sequence of project tasks is presented by sub- sequences of tasks which should be performed in determined time interval.

- Inducing students to collaborate and lead in performance of project tasks. It consists in inducing students to collaboration and engendering students to be emergent leaders of a collaborative group. The students are induced to collaboration through setting the fixed assessments of collaborative skills and requirement of participation of every student in performance all project tasks. Engendering students to act as emergent leaders is realized through setting the fixed assessments of accountability skills and a requirement of leading performance of determined project tasks. The requirement is each student should be an emergent leader in performing fixed quality of project tasks. Realization of the requirement provides sharing accountability of students for performance of the tasks. A student of a collaborative group choices tasks for leading their performance. The choice of a student is caused by his (her) willingness, desire, and possibility. Then, final assignment of emergent leaders is attained by coordination of student choices promoted by an instructor. The emergent leader is accountable for quality and timeliness of performance of the tasks which he (she) guides.

\subsection{AKM Outcome}

AKM outcome comprises assessments of students' knowledge after a sample-project completion; assessments of students' knowledge after collaborative performance of group projects; assessments of group projects, assessments of accountability skills, assessment of collaborative skills, and complex summative assessment of students.

Assessment of student knowledge built as a result of a sample-project performance is realized by the instructor through control tests relative to different knowledge levels. If a student fulfills the tests of a certain knowledge level correctly it means he has knowledge at that level. Then assessment of a student equals initial assessment set for this knowledge level. If a student doesn't fulfill the tests of a certain knowledge level not completely then the corresponding assessment is marked.

Assessment of students' knowledge after collaborative performance of a group project is realized by the instructor as a result of their examination through the control tests. Adaptation of control tests to student knowledge is realized: a student having the more high adaptive assessment is examined by more complex control tests. Fulfillment of the control tests correctly by a student means presence of corresponding knowledge. Then assessment of a student equals adaptive assessment is set for this student. If a student didn't correctly or completely fulfill the control tests, then the corresponding assessment is marked.

Assessment of performed group projects is realized due to responses of the students on control questions during presentation of the projects. If students of a collaborative group response on the questions completely and correctly then project assessment is equal fixed assessment.

Assessment of collaborative skills is based on analysis of knowledge assessments of the students received after completion of a group project. The objective of the analysis is to determine the student (or students) who obtained a maximal assessment. Such assessment is a result of the development of knowledge by students due to collaborative performance of project tasks. It can serve as a measure of success of collaboration of a student with other students of the collaborative group and also with students of other collaborative groups. Hence, a student having maximal assessment of knowledge possesses the best collaborative skill. The assessments of collaborative skill of study group students are calculated proportionally to the knowledge assessments on the basis of fixed assessment of collaborative skill.

Assessments of accountability skills of the emergent leaders are determined relative to fixed assessment of accountability skill. Assessment of an emergent leader is realized by examination of performance of project tasks guided by a leader according to task-relevant knowledge. If students' knowledge used for performing a task equals task-relevant knowledge, then an emergent leader receives maximum assessment of accountability skill relative to a task. This assessment equals fixed assessment of accountability skills. If knowledge used for performance of a task is not equal task-relevant knowledge, then an emergent leader doesn't receive maximum assessment of accountability skills 
relative to a task. Assessment of accountability skill of an emergent leader is calculated as average assessment from assessments of accountability skills relative to tasks guided by the emergent leader.

Complex summative assessment of students comprises assessments of student knowledge after completion of the sample project, and summative assessments their knowledge and skills after completion of the group projects. Assessment of student knowledge after completion of the sample project is determined as sum of assessments his (her) knowledge relative to different knowledge levels. Summative assessment of knowledge and skills of a student is calculated as sum of assessment of his (her) knowledge, assessment of accountability skills, assessment of collaboration skills, and assessment of the group project. These assessments are received after completion of the group project.

\section{Conclusion}

The proposed approach is devoted to development of the AKM process of PBL setting the order of adaptations to knowledge dynamics of students. The determined conceptual framework comprises the concepts that underlie the development of the adaptive process for managing knowledge. The process is realized by two phases: planning knowledge development, and adaptive management of knowledge development.

The approach leads to effective development of knowledge, collaborative and accountability skills of students through: detailed planning knowledge development; guiding adaptive process for managing knowledge; finding the correct balance between personalized and collaborative learning; promoting knowledge sharing among students through interactions during collaborative project work owing to adaptive grouping students and setting of a fixed assessment of collaborative skills; stimulating creation of higher-order knowledge by adjustment of the assessments to knowledge dynamics of students and adaptive assigning group projects; inducing students to knowledge utilization for effective performance of a group project owing to setting adaptive knowledge assessments for collaborative groups and a fixed assessment of accountability skills; realizing complexity of students' assessment by forming the combined assessments of knowledge, collaborative and accountability skills.

\section{References}

Aguilar, G., \& Kaijiri, K. (2007). Design overview of an adaptive computer-based assessment system, Interactive Educational Multimedia, 14, 116-130. http://www.raco.cat/index.php/iem/article/viewFile/205325/273863

Barkley, E., Cross, K. P., \& Howell, M. C. (2004).Collaborative learning techniques: A handbook forcollege faculty (Paperback), 1 edition, San Francisco, CA: Jossey-Bass

Biggs, J. (2003). Teaching for quality learning at university, 2nd ed., New York, NY: Mc Graw Hill

Brusilovsky, P., \& Maybury, M. T. (2002). From adaptive hypermedia to the adaptive web. Communications of the ACM, 45(5), 30-33. http://dx.doi.org/10.1145/506218.506239

Brusilovsky, P., \& Peylo, C. (2003). Adaptive and intelligent web-based educational systems. International Journal of Artificial Intelligence in Education, 13, 156-169.

Burgos, D., Tattersall, C., \& Koper, E. J. R. (2006). Representing adaptive e-learning strategies in IMS learning design. In R. Koper \& K. Stefanov (Eds.), Proceedings of the International Workshop in Learning Networks for Lifelong Competence Development, 54-60, March, 30-31, Sofia, Bulgaria: TENCompetence Conference. http://hdl.handle.net/1820/601

Dalkir, K., \& Liebowitz, J. (2011). Knowledge management in theory and practice, second edition, Cambridge, MA: The MIT Press

Dillenbourg, P. (1999). Introduction: What do you mean by collaborative learning? Dillenbourg (ed.), Collaborative learning. Cognitive and computational approaches, Amsterdam: Elsevier

Dongsik, K., \& Seunghee, L. (2002). Designing collaborative reflection supporting tools in E-project-based learning environments, Journal of Interactive Learning Research, 13(4), 375-392.

Doyle, T., \& Taqq, J. (2008). Helping students learn in a learner-centered environment: A Guide to facilitating learning in higher education, Sterling, Virginia: Stylus Publishing Edwards, John, S., editor (2015). The essentials of knowledge management, UK: Palgrave Macmillan. http://dx.doi.org/10.1057/9781137552105

Ettington, D. R., \& Camp, R. R. (2002). Facilitating transfer of knowledge between group projects and work teams, Journal of Management Education, 26(4), 356-379. http://dx.doi.org/10.1177/105256290202600404

Garner, S. (2010).Personal knowledge management and student learning, Journal of Business \& Economics Research, 8(12), $43-48$.

Graham, C. R., \& Misanchuk, M. (2003). Computer-mediated learning groups: benefits and challenges to using groupwork in online learning environments, In T.S. Roberts(ed) Online Collaborative Learning: Theory and 
Practice, Hershey, PA: Information Science Publishing

Jonassen, D. (2004). Design of constructivist learning environment. http://www.coe.missouri.edu/ jonassen/courses/CLE/

Lazarinis, F., Green, S., \& Pearson, E. (2010). Creating personalized assessments based on learner knowledge and objectives in a hypermedia Web testing application. Computers \& Education, 55(4), 1732-1743. Elsevier. http://dx.doi.org/10.1016/j.compedu.2010.07.019

Livingstone, D. W., \& Guile, D. (2012). The knowledge economy and lifelong learning: A critical reader, Rotterdam: Sense Publishers

Lopez, A. V. et al. (2002). Embedding facilitation in group support systems to manage distributed group behavior, Proceedings of the 35th Annual Hawaii International Conference on System Sciences, 7-10 Jan. http://dx.doi.org/10.1109/HICSS.2002.993939

Markham, T. (2012). Project based learning. Design and coaching guide, San Rafael, CA: Heart IQ Press

Mcinerney, C. R., \& Day, R. E. (2007). Rethinking knowledge management: From knowledge objects to knowledge processes, 1 edition, Springer Berlin Heidelberg

Mennin, S. (2007). Small-group problem-based learning as a complex adaptive system, Teaching and Teacher Education, 23(3), 303-313 http://dx.doi.org/10.1016/j.tate.2006.12.016

Mergendoller, et al. (2006). Pervasive management of project based learning: teachers as guides and facilitators, Buck Institute for Education http://bie.org/images/uploads/general/25a07c3bc2b40118ba8b03334fe16d58.pdf

Mergendoller, J., \& Thomas, J. W. (2005). Managing project-based learning: principles from the field. http://www.bie.org/tmp/research/researchmanagePBL.pdf

Oliver, R., \& Herrinton, J. (2001). Teaching and learning online. A beginner guide to e-learning and e-teaching in higher education, Centre for Research in Information Technology and Communications

Orvis, K. L., \& Lassiter, A. L. R. (2008). Computer-supported collaborative learning. Best practices and principles for instructors, Hershey, PA: Information Science Reference

Papanastasiou, E. (2014). Adaptive assessment, Encyclopedia of Science Education, Springer, 1-2, http://dx.doi.org/10.1007/978-94-007-6165-0

Petrides, L. A., \& Nodine, T. R. (2003). Knowledge management in education: defining the landscape. The Institute for the Study of Knowledge Management in Education http://files.eric.ed.gov/fulltext/ED477349.pdf

Quinn, J., Anderson, P., \& Finkelstein, S. (1998). Managing professional intellect, Harvard Business Review on Knowledge Management, Harvard Business School Press, 181-205.

Rooney, D., Mc Kenna, B., \& Liesh, P. (2014). Wisdom and management in the knowledge economy, Routledge, Reprint edition

Sallis, E., \& Jones, G. (2002). Knowledge management in education: enhancing learning and education, London: Kogan Page

Sherif, K. (2006). An adaptive strategy for managing knowledge in organizations, Journal of Knowledge Management, 10(4), 72-80. http://dx.doi.org/10.1108/13673270610679372

Soller, A. (2007). Adaptive support for distributed collaboration. In: Brusilovsky A., Kobsa A. \& Nejdl W.(eds), The Adaptive Web. Methods and Strategies of Web Personalization, Springer

Stanton, P., \& Fairfax, D. (2007). Establishing individual accountability for learning in an exam-less, group project course, Proceedings of the 2007 Middle Atlantic Section Fall Conference of the American Society for Engineering Education, 1-9.

Thomas, J. W. (2000). A review of research on project-based learning. http://www.autodesk.com/foundation

Tiwana, A. (1999). The knowledge management toolkit. Practical techniques for building a knowledge management system, Prentice Hall

Weinberger, A. et al. (2003). Facilitating collaborative knowledge construction in computer-mediated learning with structuring tools, Research report No.158, Munich, Germany: Ludwig-Maximilians-University, Institute for Empirical Pedagogy and Pedagogical Psychology. http://epub.ub.uni-muenchen.de/266/1/FB_158

Zaim, H., Tatoglu, E., \& Zaim, S. (2007). Performance of knowledge management practices: a causal analysis, Journal of Knowledge Management, 11(6), 54-67. http://dx.doi.org/10.1108/13673270710832163

\section{$(\mathrm{Cc}) \mathrm{BY}$}

This work is licensed under a Creative Commons Attribution 3.0 License. 